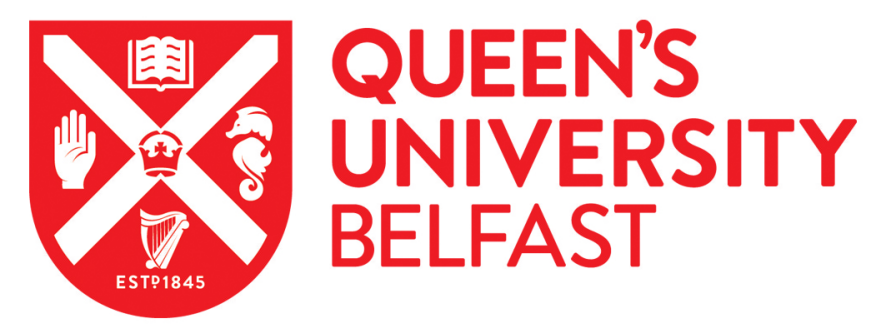

\title{
Thermal behavior and kinetics of co-pyrolysis of cellulose and polyethylene with the addition of transition metals
}

Wang, Z., Shen, D., Wu, C., \& Gu, S. (2018). Thermal behavior and kinetics of co-pyrolysis of cellulose and polyethylene with the addition of transition metals. Energy Conversion and Management, 172, 32-38.

https://doi.org/10.1016/j.enconman.2018.07.010

Published in:

Energy Conversion and Management

Document Version:

Peer reviewed version

Queen's University Belfast - Research Portal:

Link to publication record in Queen's University Belfast Research Portal

Publisher rights

Copyright 2018 Elsevier.

This manuscript is distributed under a Creative Commons Attribution-NonCommercial-NoDerivs License

(https://creativecommons.org/licenses/by-nc-nd/4.0/), which permits distribution and reproduction for non-commercial purposes, provided the author and source are cited.

\section{General rights}

Copyright for the publications made accessible via the Queen's University Belfast Research Portal is retained by the author(s) and / or other copyright owners and it is a condition of accessing these publications that users recognise and abide by the legal requirements associated with these rights.

Take down policy

The Research Portal is Queen's institutional repository that provides access to Queen's research output. Every effort has been made to ensure that content in the Research Portal does not infringe any person's rights, or applicable UK laws. If you discover content in the Research Portal that you believe breaches copyright or violates any law, please contact openaccess@qub.ac.uk. 


\section{Thermal behavior and kinetics of co-pyrolysis of cellulose and polyethylene with the addition of transition metals}

${ }^{a}$ Key Laboratory of Energy Thermal Conversion and Control of Ministry of Education, Southeast

${ }^{\mathrm{b}}$ School of Engineering and computer science, University of Hull, Hull HU6 7RX, United

Kingdom
${ }^{\mathrm{c}}$ Faculty of Engineering and Physical Sciences, University of Surrey, Guilford, GU2 7XH, United Kingdom

Abstract: The influence of the addition of transition metals involving nickel (Ni), cobalt $(\mathrm{Co})$, iron $(\mathrm{Fe})$ and manganese $(\mathrm{Mn})$ on the thermal behavior and kinetic of copyrolysis of cellulose (CL) together with polyethylene (PE) was investigated according to thermogravimetric analysis (TGA). It is found that the involvement of transition metals acting as catalysts could promote the decomposition of individual component (CL and PE) in the mixture. The initial decomposition temperature of CL and PE in the mixture is reduced by $91-136^{\circ} \mathrm{C}$ and $8-15^{\circ} \mathrm{C}$, respectively, after the addition of transition metals in comparison with that of the mixture of CL and PE. Meanwhile, transition

\footnotetext{
* Corresponding authors:

Dekui Shen, Tel:+86-13851706572; E-mail: 101011398@seu.edu.cn;

Chunfei Wu, Tel: 44-1482466464; E-mail: c.wu@hull.ac.uk.
} 

behavior

metals could intensify the synergistic interactions between CL and PE, especially during the pyrolysis stage assigned to CL decomposition. The maximum difference of weight loss in this stage is $-9.30 \% \sim-14.10 \%$ for transition metals treated-mixtures while that of the mixture without transition metal treatment is $-2.99 \%$. Kinetic results show that the co-pyrolysis of transition metal-involved CL/PE mixtures can be well described as two consecutive first order reactions. The activation energy (E) of CL and PE in the mixture is reduced by $53.21-80.53 \mathrm{~kJ} / \mathrm{mol}$ and $8.23-12.36 \mathrm{~kJ} / \mathrm{mol}$, respectively, as transition metals were involved. In addition, the content of transition metal makes a large influence on the thermal behavior and kinetics of co-pyrolysis of CL/PE mixture.

Key words: Catalytic co-pyrolysis; Cellulose; Polyethylene; Transition metal; Thermal 


\section{Introduction}

Biomass is considered to be one of the most important renewable sources in nature. It is estimated that the world's annual biomass production is up to 146 billion tons [1]. At the same time, biomass is largely produced as a by-product of industry, agriculture and forestry such as bioethanol fermentation, pulp and paper manufacturing, grain planting, and forest mining [2]. For example, biomass waste derived from agricultural production is estimated to be as many as 30 billion tons per year and that from pulp and paper industry can reach 70 million tons per year as well [3]. On the other hand, plastics are extensively used in our daily lives to bring us considerable convenience. It is reported that the global annual production of plastics in 2015 was estimated to have come to 322 million tons [4]. As a consequence, large amount of plastic related wastes are generated causing serious environmental issues due to their high biochemical stability in environment. Although various conventional methods for the disposal of biomass and plastics have been developed, the management of these wastes is still challenging. Moreover, the technology to process these wastes such as incineration and landfill would bring about many potential secondary hazards to the health of human being and the environment $[5,6]$. Accordingly, it appears much urgent to develop some green and available approaches to deal with the increasing production of biomass and plastic wastes.

Co-pyrolysis is a promising technique to simultaneously process biomass and plastic and produce high-value added products such as bio-oil and chemicals [7, 8]. It is 
reported that the bio-oil directly derived from biomass generally presented a nature of high oxygen content, acidity, instability, viscosity and corrosion which highly restricted its applications [1,9]. On the contrary, plastic contains high hydrogen content presenting a high effective hydrogen to carbon ratio [10]. Plastic can provide biomass with abundant hydrogen atoms (serving as hydrogen donor) to intensify the thermal decomposition of biomass and reduce the polycondensation of the intermediate products as it was employed to co-pyrolyze with biomass. Meanwhile, the oxygenated compounds originated from biomass during the co-pyrolysis process could promote the chain scission and cracking of plastic in return [11]. As a result, the quality and yield of targeted products (bio-oil or chemicals) were significantly improved. It is reported by Dorado et al. that the yield of alkyl benzenes from the catalytic fast pyrolysis of CL along with polyethylene terephthalate was greatly enhanced compared with CL alone [12]. Kositkanawuth et al. found that co-pyrolysis of biomass with polystyrene led to the improvement of the quality and quantity of the oil compared to pyrolysis of Sargassum alone [13]. Particularly, the oil quantity increased from 3\% for Sargassum alone to $29 \%$ for the mixture of $67 \%$ Sargassum and $33 \%$ polystyrene.

It is notable that the involvement of catalyst during the co-pyrolysis of biomass and plastic would further improve the quality of bio-oil compared to that without catalyst. The presence of catalyst can serve active sites for the decomposition of raw materials and the interaction of the intermediates. For example, the surface acid sites of HZSM5 zeolite can promote the catalytic cracking and refining reactions of biomass and its 
mixture together with plastic to de-oxygenate bio-oil, favoring the production of hydrocarbon products [14]. At the same time, the catalyst with unique porosity structure is efficient to enhance the selectivity of desired products. Kim et al. found that HY zeolite with a large pore size $(7.4 \times 7.4 \AA)$ and cavities could be favorable for the diffusion of reactant molecules from the co-pyrolysis of CL and polypropylene into internal pores, resulting in the enhancement of the yields of aromatic hydrocarbons [15]. On the contrary, using a catalyst with pore size smaller than raw material (CL with a kinetic diameter of $8.6 \AA$ ) resulted in the reactions mainly occurred at external surface of the catalysts which greatly restricted the catalytic reaction [15]. Up to date, the catalysts employed are those with unique physicochemical characteristics mainly concerning zeolites and metal oxides [7, 16-18]. For example, LOSA-1, spent FCC and $\gamma-\mathrm{Al}_{2} \mathrm{O}_{3}$ were employed as catalysts during a catalytic co-pyrolysis of PE and blackliquor lignin for the production of petrochemicals and these catalysts were consequently proven to be effective in the catalytic conversion [17]. In the co-pyrolysis of CL and polypropylene, microporous zeolites (ZSM-5) was found to be more favorable in the formation of aromatic hydrocarbons in comparison with mesoporous Al-SBA-15 [16].

Transition metals especially for $\mathrm{Ni}, \mathrm{Co}, \mathrm{Fe}$ and $\mathrm{Mn}$ have been widely applied in various fields such as catalytic pyrolysis of biomass for the preparation of high quality bio-oil $[19,20]$. It was found that the involvement of $\mathrm{Ni}$ and Fe could simultaneously catalyze rearrangement reactions and promote depolymerization of biomass which were favorable for the preparation of desired pyrolysis products such as fuels, chemicals [21]. 
Meanwhile, transition metals are the necessary minerals for the growth of plant, which are extensively disperse in biomass $[22,23]$. In this work, transition metals have been used for the co-pyrolysis of biomass and plastic. We aims to develop a new, low-cost and high-efficient catalyst for the catalytic co-pyrolysis of biomass and plastic blend, and assess the effect of natural biomass with intrinsic transition metals on its copyrolysis process. Particularly, CL and PE were employed as the representatives of biomass and plastic, respectively. The thermal behavior and kinetics of co-pyrolysis of the mixtures affected by the type of transition metals ( $\mathrm{Ni}, \mathrm{Co}, \mathrm{Fe}$ and $\mathrm{Mn}$ ) and the concentration of catalyst (Ni) were investigated according to TGA at ambient temperature to $750{ }^{\circ} \mathrm{C}$ under nitrogen atmosphere.

\section{Materials and methods}

\subsection{Raw materials}

Commercially available CL (CAS number 9004-34-6) in the form of microcrystalline powders was purchased from Sigma-Aldrich Corporation (St. Louis, MO, USA). PE powder (CAS number 9002-88-4) with average $\mathrm{M}_{\mathrm{w}}$ and $\mathrm{M}_{\mathrm{n}}$ of $\sim 4000$ and $\sim 1700$ by GPC, respectively, was provided by Sigma-Aldrich Corporation (St. Louis, MO, USA). The detailed elemental composition and chemical structure of CL and PE are presented in Table S1 and Fig. S1. Transition metal nitrates including nickel nitrate hexahydrate (Ni), cobaltous nitrate hexahydrate (Co), iron nitrate nonahydrate (Fe) and manganese nitrate tetrahydrate (Mn) were purchased from Sigma-Aldrich Corporation (St. Louis, MO, USA). 


\subsubsection{Preparation of samples}

126

For the preparation of Ni-involved CL/PE mixture, $1 \mathrm{~g}$ CL powder was immersed into a $20 \mathrm{~mL}$ of $0.1 \mathrm{~mol} / \mathrm{L} \mathrm{Ni}$ solution. The mixed suspension was stirred at $60{ }^{\circ} \mathrm{C}$ for $3 \mathrm{~h}$ to evaporate and then dried at $105^{\circ} \mathrm{C}$. Afterward the dried powder was collected and mixed with $1 \mathrm{~g}$ PE powder in an agate mortar via manual grinding for $20 \mathrm{~min}$. The as-grinded powder was the targeted mixture of $C L$ and $P E$ in a ratio of $1: 1$ with a Ni concentration of $1 \mathrm{mmol} \mathrm{Ni/g}$ mixture, which was labeled as CL/PE-Ni-1. CL/PE mixture with different dosage of $\mathrm{Ni}(0,0.25,0.5,0.75$ and $1 \mathrm{mmol} \mathrm{Ni} / \mathrm{g}$ mixture $)$ and different type of transition metals as catalysts $(\mathrm{Ni}, \mathrm{Co}, \mathrm{Fe}, \mathrm{Mn})$ were prepared in the similar process via regulating the concentration of $\mathrm{Ni}$ solution and catalyst solution type, respectively. For comparison, CL/PE mixture without catalyst and $\mathrm{CL}$ with $1 \mathrm{mmol} / \mathrm{L}$ transition catalyst (i.e., CL-Ni-1, CL-Co-1, CL-Fe-1 and CL-Mn-1) were also prepared.

\subsubsection{Thermogravimetric analysis}

The pyrolysis experiments were carried out in a thermogravimetric analyzer (Metteler Toledo 188 TGA/SDTA 851, Switzerland) to investigate the thermal decomposition profiles of CL and PE and their mixtures with or without catalysts. About $10 \mathrm{mg}$ of sample was pyrolyzed under $0.1 \mathrm{~m}^{3} / \mathrm{min}_{2}$ flow at a heating rate of $10{ }^{\circ} \mathrm{C} / \mathrm{min}$ from room temperature to $750{ }^{\circ} \mathrm{C}$. More than two parallel runs were carried out for all the experiments to ensure low relative errors (below 5\%). 


\subsection{Kinetic study}

147 Kinetic parameters such as activation energy (E) and pre-exponential factor (A) can be 148 employed to qualitatively describe the pyrolysis characteristics of reactant which can 149 be calculated according to DTG data. It is assumed that the pyrolysis of solid fuel such 150 as coal, plastic and biomass belongs to a first order reaction and can be expressed as 151 following equation (Eq. 1):

$152 \quad \frac{d x}{d t}=A \exp \left[\left(\frac{-E}{R T}\right)(1-x)\right]$

153 where $\mathrm{E}$ is activation energy $(\mathrm{kJ} / \mathrm{mol}), \mathrm{A}$ is pre-exponential factor $(1 / \mathrm{min}), \mathrm{T}$ is temperature $(\mathrm{K}), \mathrm{t}$ is time $(\mathrm{min}), \mathrm{R}$ is a universal gas constant $(\mathrm{J} / \mathrm{mol} \mathrm{K}), \chi$ is conversion

155 of raw material which can be obtained from the following equation (Eq. 2)

$156 x=\frac{W_{0}-W_{\text {time }}}{W_{0}-W_{\text {final }}}$

157 where $\mathrm{W}_{0}$ is the initial mass of sample $(\mathrm{mg}), \mathrm{W}_{\text {time }}$ and $\mathrm{W}_{\text {final }}$ are the mass of sample at 158 time $\mathrm{t}$ and at the end of pyrolysis, respectively. For a constant heating rate $\mathrm{H}(\mathrm{H}=\mathrm{dT} / \mathrm{dt})$ 159 during pyrolysis, Eq. 1 can be integrated as following equation (Eq. 3):

$160 \ln \left[\frac{-\ln (1-x)}{T^{2}}\right]=\ln \left[\frac{A R}{H E}\left(1-\frac{2 R T}{E}\right)\right]-\frac{E}{R T}$

161 Based on most $\mathrm{E}$ values and temperature range during pyrolysis, $\mathrm{RT} / \mathrm{E}<<1$, thus the 162 expression $\ln [\mathrm{AR} / \mathrm{HE}(1-2 \mathrm{RT} / \mathrm{E})]$ can be considered as a constant. The slope and the 163 intercept of the plots of $\ln \left[-\ln (1-\chi) / \mathrm{T}^{2}\right]$ versus $1 / \mathrm{T}$ according to Eq. 3 are $\mathrm{E}$ and $\mathrm{A}$, 164 respectively. 
165

166

167

168

169

170

171

172

173

174

175

176

177

178

179

180

181

182

183

184

185

186

\section{Results and discussion}

\subsection{Pyrolysis characteristics}

3.1.1 CL with or without transition metals, PE and CL/PE mixture

Fig. 1 shows TG and DTG curves of pyrolysis of CL with or without transition metals catalysts (CL, CL-Ni-1, CL-Co-1, CL-Fe-1 and CL-Mn-1), PE and CL/PE mixture under $\mathrm{N}_{2}$ atmosphere from ambient temperature to $750^{\circ} \mathrm{C}$ at a heating rate of $10^{\circ} \mathrm{C} / \mathrm{min}$. Corresponding pyrolysis parameters are showed in Table S2.

It can be seen that CL showed a good thermal stability before $300{ }^{\circ} \mathrm{C}$ with only $2.83 \mathrm{wt} . \%$ weight loss which can be attributed to its high crystallinity. After that, CL underwent a fast weight loss stage taking place at $314-373{ }^{\circ} \mathrm{C}$ (see TG curve in Fig. 1a) with $78.37 \mathrm{wt} . \%$ weight loss. This result was well in agreement with a previous study where the same feedstock (CAS number 9004-34-6) was investigated [24]. It is reported that the great weight loss of CL in this stage was mainly related to the fast decomposition of CL into volatile matters involving liquid products $\left(\operatorname{tar}\right.$ and $\left.\mathrm{H}_{2} \mathrm{O}\right)$ and permanent gases $\left(\mathrm{CO}, \mathrm{CO}_{2}\right.$, $\mathrm{H}_{2}$ and $\left.\mathrm{CH}_{4}\right)[25,26]$. With the further increase of reaction temperature, the pyrolysis of CL came into a slow carbonization stage $\left(373-750^{\circ} \mathrm{C}\right)$. In this stage, $\mathrm{CL}$ continued to lose weight in a slight extent resulting from the release of small molecular gases from the rearrangement of solid phase [21]. 10.67wt.\% solid residue (char) was obtained at the end of the experiment. The DTG curve in Fig. 1b illustrated that the main decomposition stage of CL exhibited a narrow weight loss peak with a maximum weight lost rate of $-26.89 \mathrm{wt} . \% / \mathrm{min}$ at $349^{\circ} \mathrm{C}$. 

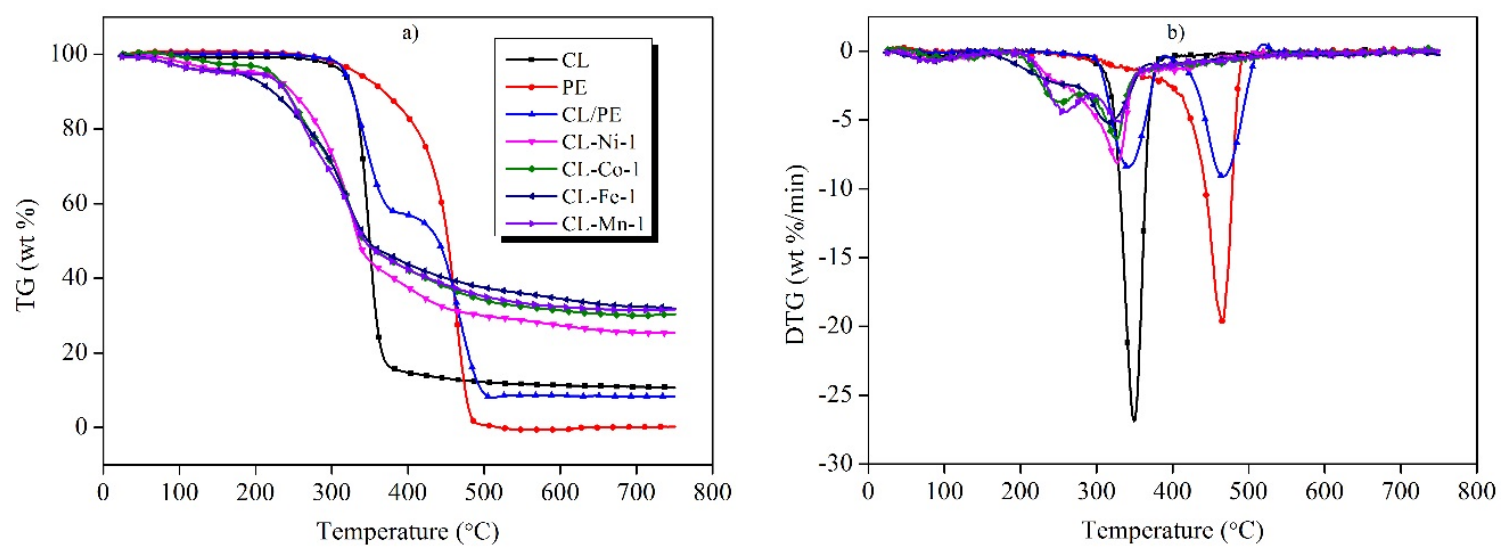

187

Fig. 1 Pyrolytic behavior of CL with or without transition metals catalysts, PE and CL/PE mixture: a) TG curves, b) DTG curves

The decomposition of CL with transition metals treatment (CL-Ni-1, CL-Co-1, CL-Fe1 and CL-Mn-1) was composed of three stages. The first stage occurred at $80-170{ }^{\circ} \mathrm{C}$ referring to $3.26 \mathrm{wt} . \%-4.75 \mathrm{wt} . \%$ weight loss, which resulted from the loss of water and low volatile compounds [27]. The weight loss of CL with transition metals treatment at this stage was slightly higher than that of the pure CL, revealing that the introduction of transition metals can improve the hydrophilicity of CL. Collard et al. proposed that the introduction of transition metals such as Fe and Ni would weaken some hydrogen bonds of CL and partly promote the transformation of crystalline CL to amorphous phase one [25]. As a consequence, more water content was involved during the pyrolysis of the transition metal-treated CL. At the same time, the involvement of transition metals was also found to be effective in catalyzing the formation of condensable products and incondensable gas in this stage, resulting in a larger mass loss compared to pure CL [26]. The decomposition of CL-Ni-1, CL-Co-1, CL-Fe-1 and CL-Mn-1 at about $179-350{ }^{\circ} \mathrm{C}$ and $350-750{ }^{\circ} \mathrm{C}$ were assigned to the main decomposition stage and carbonization stage, respectively. The decomposition of CL- 
Ni-1, CL-Co-1, CL-Fe-1 and CL-Mn-1 started at 219, 210, 179 and $223^{\circ} \mathrm{C}$, respectively, which was $91-135^{\circ} \mathrm{C}$ lower than that of pure CL. It was reported that transition metal ions could serve as Lewis acid sites to promote the dehydration and other depolymerization of CL [25]. The initial decomposition temperature of the transition metal-treated CLs was negatively related to the Lewis acidity intensity of the transition metal employed, yielding to an order of $\mathrm{Mn}>\mathrm{Ni}>\mathrm{Co}>\mathrm{Fe}$.

DTG curves in relation to the transition metal-treated CL are shown in Fig. 1b. It can be found that CL-Ni-1 and CL-Fe-1 presented a sole weight loss peak while two weight loss peaks were observed in CL-Co-1 and CL-Mn-1, respectively. The maximum weight loss rate of CL-Ni-1, CL-Co-1, CL-Fe-1 and CL-Mn-1 was located at 327, 327, 318 and $313{ }^{\circ} \mathrm{C}$, respectively. These temperatures have been shifted to lower temperature compared to pure $\mathrm{CL}\left(349^{\circ} \mathrm{C}\right)$. It further confirmed that the involvement of transition metals was favorable for the catalytic decomposition of CL. The shoulder peak in CLCo-1 and CL-Mn-1 was believed to be related to the decomposition of amorphous CL, which rose from the transformation of crystalline CL into amorphous CL under the presence of certain catalyst [28]. Similar results can be found in previous studies [28, 29].

The weight loss of PE shown in Fig. 1a was negligible before $300{ }^{\circ} \mathrm{C}$ due to its crystal structure having high thermal stability. PE started to gradually decompose after $335^{\circ} \mathrm{C}$ and emerged a sharp weight loss at $424-490{ }^{\circ} \mathrm{C}$. During this decomposition period, PE 
was totally decomposed without solid residue which was coincided with its low fixed carbon content (Table S1). DTG curve further reveals that PE showed a maximum weight loss rate of $-19.63 \mathrm{wt} . \% / \mathrm{min}$ at $466{ }^{\circ} \mathrm{C}$.

For blending CL together with PE, the as-obtained mixture showed two successive weight loss stages at $314-385^{\circ} \mathrm{C}$ and $422-511^{\circ} \mathrm{C}$ which were assigned to the weight loss of CL and PE, respectively. CL and PE were mostly decomposed in their corresponding stage showing two narrow weight loss peaks (Fig. 1b). The temperature of the maximum weight loss rate of the mixture of CL and PE is 342 and $467^{\circ} \mathrm{C}$, respectively, which is slightly different from those of raw materials (pure CL and PE), indicating that interactions were occurred in the pyrolysis of the mixture. The solid reside after decomposition (Fig. 1a) was $8.35 \mathrm{wt} . \%$ which was much higher than the theoretical one (5.33wt.\%) calculated in terms of the mixture ratio of CL and PE, further demonstrating that there was an interactions existed in CL/PE mixture. Matsuzawa et al. suggested that the presence of plastic can fascinate the dehydration, decarbonylation and decarboxylation of CL inhibiting the depolymerization process [26].

\subsubsection{CL/PE mixture with transition metal catalyst}

Fig. 2 shows the TG and DTG curves of CL/PE mixture with or without transition metals catalysts (CL/PE-Ni-1, CL/PE-Co-1, CL/PE-Fe-1 and CL/PE-Mn-1) at a heating rate of $10^{\circ} \mathrm{C} / \mathrm{min}$ from room temperature to $750^{\circ} \mathrm{C}$. The weight loss of transition metal treated-CL/PE mixture was mainly composed of three stages, i.e., $73-206{ }^{\circ} \mathrm{C}, 178$ - 
$319^{\circ} \mathrm{C}$, and $406-509^{\circ} \mathrm{C}$, which were assigned to the loss of water and the decomposition of CL and PE, respectively (Fig. 2a). It is worth noting that the decomposition temperature of CL significantly decreased during the pyrolysis of the mixture of CL and PE after the introduction of transition metals. For example, the initial decomposition temperature decreased from $314{ }^{\circ} \mathrm{C}$ to $223{ }^{\circ} \mathrm{C}$ when the sample was changed from CL/PE to CL/PE-Ni-1. The initial decomposition temperature was reduced to $211^{\circ} \mathrm{C}$ for $\mathrm{CL} / \mathrm{PE}-\mathrm{Co}-1,178^{\circ} \mathrm{C}$ for CL/PE-Fe-1 and $216^{\circ} \mathrm{C}$ for CL/PE-Mn1 , respectively (Table S2).

DTG results in Fig. 2b showed that the maximum weight loss rate of CL in CL/PE-Ni1, CL/PE-Co-1, CL/PE-Fe-1 and CL/PE-Mn-1 was at 268, 223, 233 and $236{ }^{\circ} \mathrm{C}$, respectively, which was $47-118{ }^{\circ} \mathrm{C}$ lower than that of $\mathrm{CE} / \mathrm{PE}\left(342{ }^{\circ} \mathrm{C}\right)$. The corresponding maximum weight loss temperature of CL in transition metals treatedmixtures followed the order of CL/PE-Mn-1 $\approx$ CL/PE-Co-1 $>$ CL/PE-Ni-1 $\approx$ CL/PE-Fe1. Moreover, the weight loss peak of CL/PE-Ni-1 and CL/PE-Fe-1 was broader than that of CL/PE-Mn-1 and CL/PE-Co-1. These observations indicated that the involvement of transition metals would significantly influence the pyrolysis behavior of CL in mixture. And this influence varied with the type of catalyst [25]. On the other hand, the initial decomposition temperature of PE in CL/PE-Ni-1, CL/PE-Co-1, CL/PEFe-1 and CL/PE-Mn-1 was 409, 410, 407 and $414{ }^{\circ} \mathrm{C}$, respectively, which was slightly lower than that of $\mathrm{CL} / \mathrm{PE}\left(422^{\circ} \mathrm{C}\right)$, indicating that transition metal based-catalysts were effective to promote the thermal decomposition of $\mathrm{PE}$. The other reason to explain this 
272 effectively interact with PE molecular to make contributions to PE decomposition [24].

273 The maximum weight loss rate of all samples in Fig. $2 \mathrm{~b}$ were located at about $466^{\circ} \mathrm{C}$

$\mathrm{Mn}-1$.
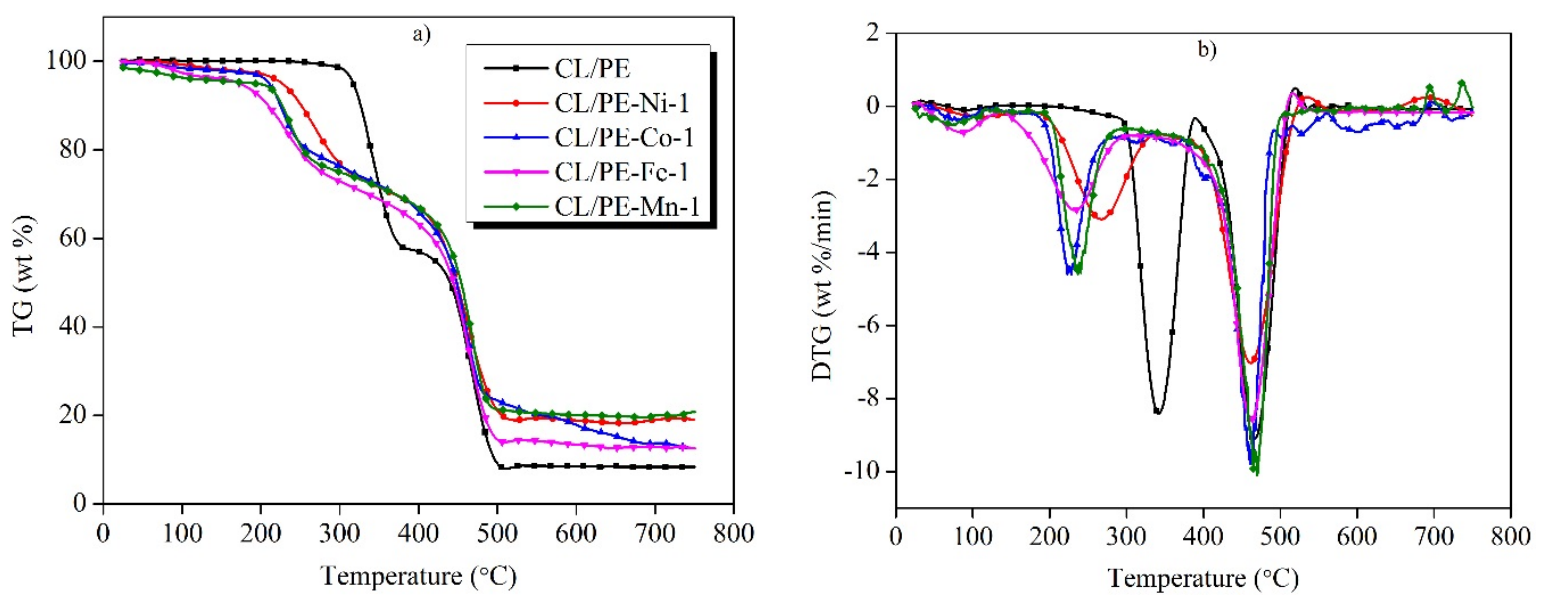

Fig. 2 Pyrolytic behavior of CL/PE mixture with or without transition metals

3.1.3 CL/PE mixture with different content of Ni catalyst

Fig. 3 shows TG and DTG curves of the CL/PE mixture with different content of Ni 
CL/PE-Ni-25, CL/PE-Ni-0.5, CL/PE-Ni-0.75 and CL/PE-Ni-1 lost 0.69wt.\%, $1.52 \mathrm{wt} . \%, 1.57 \mathrm{wt} . \%$ and $4.14 \mathrm{wt} . \%$ of total weight, respectively, which was attributed to the loss of water content. The decomposition of CL in the mixture mainly emerged at the second stage. It started at $215^{\circ} \mathrm{C}$ for $\mathrm{CL} / \mathrm{PE}-\mathrm{Ni}-0.25,207{ }^{\circ} \mathrm{C}$ for $\mathrm{CL} / \mathrm{PE}-\mathrm{Ni}-0.5$, $200{ }^{\circ} \mathrm{C}$ for $\mathrm{CL} / \mathrm{PE}-\mathrm{Ni}-0.75$ and $222{ }^{\circ} \mathrm{C}$ for $\mathrm{CL} / \mathrm{PE}-\mathrm{Ni}-1$, respectively. The initial decomposition temperature decreased with the increase of $\mathrm{Ni}$ content and reached a minimum value as the $\mathrm{Ni}$ content in mixture was $0.75 \mathrm{mmol} / \mathrm{g}$.

At the same time, DTG results in Fig. $3 b$ reveal that the temperature of the maximum weight loss rate of CL in CL/PE-Ni-0.25, CL/PE-Ni-0.5, CL/PE-Ni-0.75 and CL/PENi-1 is $280,273,271$ and $268{ }^{\circ} \mathrm{C}$, respectively. The temperature showed a negative relationship with the Ni content involved in mixture. The maximum weight loss rate of CL/PE-Ni-25 was $-4.71 \mathrm{wt} . \% / \mathrm{min}$ which was obviously higher than those derived from relative high $\mathrm{Ni}$ content $(0.5-1 \mathrm{mmol} / \mathrm{g})$, indicating that the increase of $\mathrm{Ni}$ content resulted in the reduction of the intensity of weight loss. The third weight loss stage was assigned to the decomposition of PE in the mixture. It can be seen that the initial decomposition of PE is at $422{ }^{\circ} \mathrm{C}$ for $\mathrm{CL} / \mathrm{PE}, 419{ }^{\circ} \mathrm{C}$ for $\mathrm{CL} / \mathrm{PE}-\mathrm{Ni}-0.25,406{ }^{\circ} \mathrm{C}$ for CL/PE-Ni-0.5, $408^{\circ} \mathrm{C}$ for CL/PE-Ni-0.75 and $409^{\circ} \mathrm{C}$ for CL/PE-Ni-1, respectively (Fig. 3a). This observation may reveal that the increase of Ni content can provide more active catalytic sites for PE decomposition and produce more oxygenated compounds to promote the decomposition of the chains of PE [30]. On the other hand, the temperature of the maximum weight loss of PE in CL/PE-Ni-25, CL/PE-Ni-0.5, CL/PE-Ni-0.75 and 

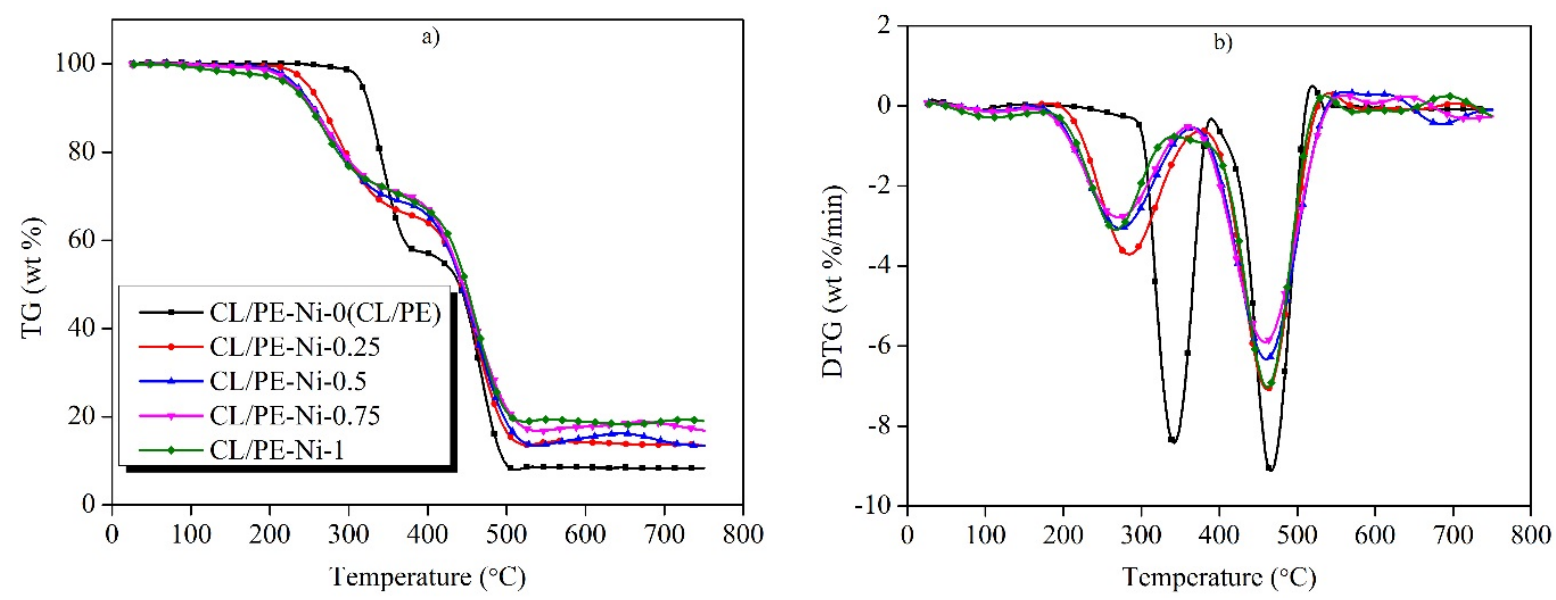

Fig. 3 Pyrolytic behavior of CL/PE mixture with different content of Ni catalyst: a)

TG curves, b) DTG curves

In order to elucidate the interaction between the individual fractions in the mixture, the difference of weight loss $(\Delta W)$ between the experimental values and the estimated ones was calculated according to the following equation (Eq. 4).

where, $W_{\text {mixture }}$ is the weight loss of CL/PE mixture with or without transition metals catalysts; $x_{1}$ and $x_{2}$ is the weight fraction of CL and PE in the mixtures, respectively; $W_{l}$ and $W_{2}$ is the weight loss of the transition metals-treated CL and PE alone. The variation of $\Delta W$ with the function of temperature for the CL/PE mixtures with or without transition metals catalysts is presented in Fig. 4. It can be seen that the variation of $\Delta W$ of $\mathrm{CL} / \mathrm{PE}$ was lower than $\pm 1.5 \%$ under $300{ }^{\circ} \mathrm{C}$. The reason for this observation was that both $\mathrm{CL}$ and PE possess relative high thermal stabilities. As a result, almost no 
interaction between CL and PE occurred at this temperature period. With the continuing increment of reaction temperature, the co-pyrolysis of the CL/PE mixture showed a slight decrease of $\Delta W$ at the temperature range of $300 \sim 330^{\circ} \mathrm{C}$ with the maximum $\Delta W$ value of $-2.99 \%$ at $322{ }^{\circ} \mathrm{C}$. At this stage, CL in the mixture started to decompose and PE was greatly melted (see Scheme S1). The softened PE coated on the surface of CL inhibiting the evolution of volatile matter [24]. Afterwards, the $\Delta W$ of CL/PE drastically rose and kept a positive value at a wide temperature range $\left(330 \sim 480{ }^{\circ} \mathrm{C}\right)$. Two overlapping peaks are observed and the corresponding maximum $\Delta W$ values of these two peaks are $7.62 \%$ at $348{ }^{\circ} \mathrm{C}$ and $14.42 \%$ at $446{ }^{\circ} \mathrm{C}$, respectively. The considerable increase of $\Delta W$ value was accounted for the drastic decompose of CL and PE (see Scheme S1). Thereafter, the variation of $\Delta W$ of CL/PE reduces to below $3 \%$ as temperature was increased above $480^{\circ} \mathrm{C}$. In particular, the variation of $\Delta W$ could be considered as a result of the synergistic interaction between CL and PE. In other words, there was a strongly synergistic interaction in the decomposition of CL and PE.

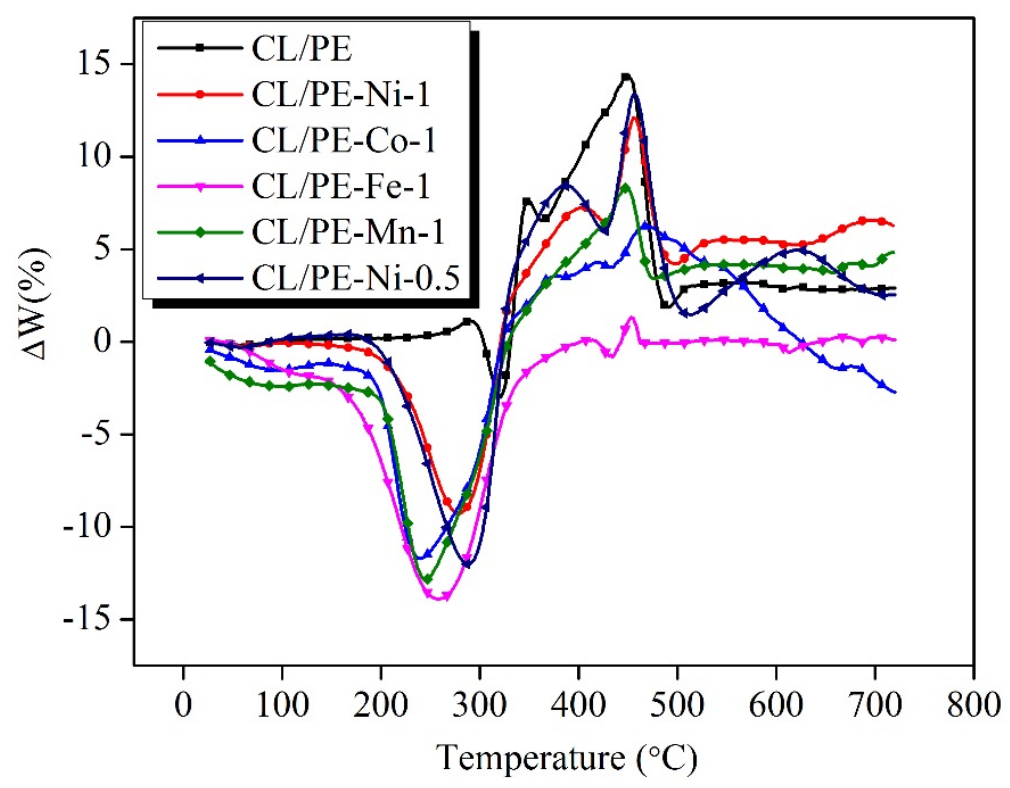


341

After the pretreatment with transition metals $(1 \mathrm{mmol} / \mathrm{g})$, the variation $\Delta W$ shows a little different trend in comparison with that of non-transition metal treated one (CL/PE) depending on the type of transition metals. After a slight variation of $\Delta W(-0.44 \% \sim-$ $2.72 \%$ ) at relatively lower temperature, the transition metals-treated CL/PE mixtures underwent a significant process in $\Delta W$ decrease at temperature $145 \sim 325^{\circ} \mathrm{C}$. In particular, the maximum $\Delta W$ value of CL/PE-Ni-1, CL/PE-Co-1, CL/PE-Fe-1 and CL/PE-Mn-1 is $-9.30 \%$ at $279{ }^{\circ} \mathrm{C},-11.72 \%$ at $238{ }^{\circ} \mathrm{C},-14.10 \%$ at $258{ }^{\circ} \mathrm{C}$ and $-12.89 \%$ at $244{ }^{\circ} \mathrm{C}$, respectively. These values are much higher than that of CL/PE $(-2.99 \%)$ under the similar stage. The results indicate that the involvement of transition metals during the co-pyrolysis of CL and PE could greatly intensify the synergistic effect of PE on CL via inhibiting the release of volatile compounds.

With the increase of pyrolysis temperature from $325^{\circ} \mathrm{C}, \mathrm{CL} / \mathrm{PE}-\mathrm{Ni}-1, \mathrm{CL} / \mathrm{PE}-\mathrm{Co}-1$, and $\mathrm{CL} / \mathrm{PE}-\mathrm{Mn}-1$ encountered a remarked rise of $\Delta W$ value while $\Delta W$ of CL/PE-Fe-1 was slightly changed $( \pm 1.3 \%)$. This observation implies that the synergistic interaction between CL and PE in the presence of transition metals-catalyst occurred in the whole pyrolysis process for the mixture. It is worth noting that the maximum $\Delta W$ value of CL/PE-Ni-1, CL/PE-Co-1, CL/PE-Fe-1 and CL/PE-Mn-1 in this stage is $12.10 \%$ at $456{ }^{\circ} \mathrm{C}, 6.23 \%$ at $468{ }^{\circ} \mathrm{C}, 1.30 \%$ at $453{ }^{\circ} \mathrm{C}$ and $8.35 \%$ at $447{ }^{\circ} \mathrm{C}$, respectively. These values are all lower than that of CL/PE (14.41\%). It hence can be concluded that the introduction of transition metals into CL/PE mixture during pyrolysis process was more effective in intensifying the influence of PE on CL rather than that of CL on PE. 
Moreover, $\Delta W$ value of CL/PE-Ni-1, CL/PE-Co-1, CL/PE-Fe-1 and CL/PE-Mn-1 at the end of pyrolysis were $6.91 \%,-2.72 \%, 0.12 \%$ and $4.95 \%$, respectively. It may result from the different catalytic performance of transition metals. The effect of Ni content on the variation of $\Delta W$ was employed to interpret the influence of catalyst concentration on the interaction of mixture samples (Fig. 4). Although the variation of $\Delta W$ of CL/PENi-0.5 exhibits a similar trend with CL/PE-Ni-1, the intensity of CL/PE-Ni-0.5 around the maximum $\Delta W$ value is stronger than that of $\mathrm{CL} / \mathrm{PE}-\mathrm{Ni}-1$. Therefore, the concentration of transition metal also plays an important role in catalyzing the decomposition of the CL/PE mixture.

\subsection{Kinetic analysis}

The kinetic analysis of all samples focuses on the main decomposition stage based on first-order reaction model. As a result, kinetic parameters, E and A, were obtained. The

377 fitting results of $\ln \left[-\ln (1-\mathrm{x}) / \mathrm{T}^{2}\right]$ versus $1 / \mathrm{T}$ of all samples are shown in Fig. 5 and 378 corresponding parameters are summarized in Table 1. It is found that correlation 379 coefficient $\left(\mathrm{R}^{2}\right)$ of all samples fitted by first-order reaction model are larger than 0.94 , 380 indicating that the employed reaction model can describe all pyrolysis process very well. 381 The pyrolysis of PE and CL with or without transition metals could be described by a 382 single first-order reaction while the mixture of CL and PE with or without transition metals could be described by two successive first-order reactions. Particularly, the first stage and second stage pyrolysis of the mixture of CL and PE are mainly attributed to 
the decomposition of CL and PE, respectively.
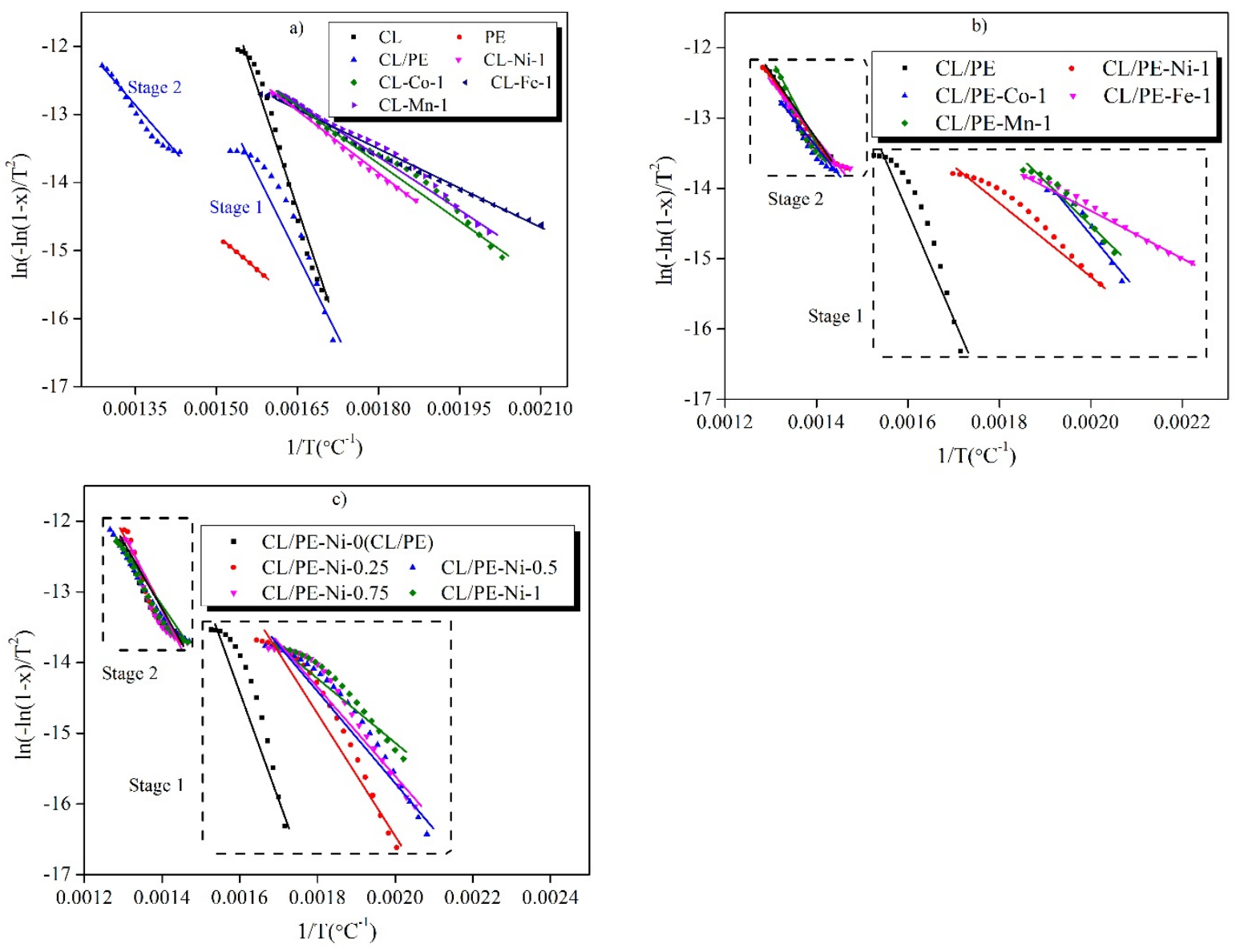

Fig. 5 Plots of $\ln \left(-\ln (1-\mathrm{x}) / \mathrm{T}^{2}\right)$ versus $1 / \mathrm{T}$ of samples, a)CL with or without transition metals, PE and CL/PE mixture; b) CL/ PE mixture with or without transition metals;

c) $\mathrm{CL} / \mathrm{PE}$ mixture with different content of $\mathrm{Ni}$ catalyst

As shown in Table 1, E value of CL and PE is 208.76 and $241.24 \mathrm{~kJ} / \mathrm{mol}$, respectively. on account of its higher thermal stability. It is found that the activation energy of CL become significantly lower as it was blended with PE (CL/PE). The activation energy assigned to CL in CL/PE was decreased by about 2 folds in comparison with that of CL. Meanwhile, the $\mathrm{E}$ of $\mathrm{PE}$ in $\mathrm{CL} / \mathrm{PE}$ was decreased by 3 folds compared to that of $\mathrm{PE}$ 
397 between CL and PE when they were co-pyrolyzed. On the other hand, apart from the

398 blending with $\mathrm{PE}$, the pretreatment with transition metals also resulted in the reduction

399 of the E value of CL. Cellard et al. confirmed that the presence of transition metal could

400 partly destroy the crystalline structure of cellulose which was favorable for its

401 degradation [25]. Amongst the transition metals employed (Ni, Co, Fe and $\mathrm{Mn}$ ), $\mathrm{Fe}$

402 seems to be the most efficient one reducing the E value of CL to $32.02 \mathrm{~kJ} / \mathrm{mol}$ (CL-Fe-

403 1). In this case, the $E$ value of CL was reduced by more than 5 folds.

404

405 Table 1 Kinetic parameters for pyrolysis of samples including CL with or without

406 catalyst, PE, and CL/PE mixture with or without catalyst

\begin{tabular}{|c|c|c|c|c|c|}
\hline Material & Temperature & $\begin{array}{l}\text { Conversion range } \\
\qquad\left(x_{1}, \%\right)\end{array}$ & $\mathrm{E}(\mathrm{kJ} / \mathrm{mol}))$ & $\mathrm{A}\left(\mathrm{min}^{-1}\right)$ & $\mathrm{R}^{2}$ \\
\hline $\mathrm{CL}$ & $314-379$ & $5.06-91.67$ & 208.76 & $1.34 \times 10^{17}$ & 0.9732 \\
\hline $\mathrm{PE}$ & $357-390$ & $8.07-85.46$ & 154.24 & $3.82 \times 10^{10}$ & 0.9981 \\
\hline \multirow[t]{2}{*}{$\mathrm{CL} / \mathrm{PE}$} & $318-384$ & $5.43-43.36$ & 120.41 & $1.22 \times 10^{9}$ & 0.9411 \\
\hline & $422-505$ & $46.36-94.09$ & 80.75 & $1.19 \times 10^{5}$ & 0.9675 \\
\hline CL-Ni-1 & $262-349$ & $16.75-68.78$ & 52.43 & $4.99 \times 10^{3}$ & 0.9963 \\
\hline CL-Co-1 & $220-347$ & $6.50-68.20$ & 44.70 & $1.01 \times 10^{3}$ & 0.9825 \\
\hline CL-Fe-1 & $203-360$ & $9.65-70.49$ & 32.02 & $5.24 \times 10^{1}$ & 0.9925 \\
\hline CL-Mn-1 & $226-350$ & $9.47-70.30$ & 41.84 & $5.65 \times 10^{2}$ & 0.9800 \\
\hline \multirow[t]{2}{*}{ CL/PE-Ni-1 } & $223-319$ & $5.08-30.31$ & 41.63 & $3.04 \times 10^{2}$ & 0.9615 \\
\hline & 409-509 & $40.14-94.16$ & 71.52 & $2.40 \times 10^{4}$ & 0.9782 \\
\hline \multirow[t]{2}{*}{ CL/PE-Co-1 } & $211-253$ & $5.05-20.16$ & 67.20 & $3.81 \times 10^{5}$ & 0.9457 \\
\hline & $416-484$ & $38.92-79.64$ & 72.52 & $2.45 \times 10^{4}$ & 0.9558 \\
\hline \multirow[t]{2}{*}{ CL/PE-Fe-1 } & $178-271$ & $5.78-25.55$ & 29.88 & $2.99 \times 10^{1}$ & 0.9909 \\
\hline & $406-499$ & $39.89-90.15$ & 67.39 & $1.09 \times 10^{4}$ & 0.9513 \\
\hline \multirow[t]{2}{*}{ CL/PE-Mn-1 } & $216-267$ & $7.86-26.93$ & 52.14 & $8.88 \times 10^{3}$ & 0.9583 \\
\hline & $429-492$ & $45.33-93.23$ & 71.80 & $4.82 \times 10^{6}$ & 0.9647 \\
\hline \multirow[t]{2}{*}{ CL/PE-Ni-0.25 } & $226-336$ & $1.50-34.62$ & 69.78 & $1.45 \times 10^{5}$ & 0.9438 \\
\hline & $419-496$ & $44.72-95.96$ & 64.55 & $2.54 \times 10^{6}$ & 0.9524 \\
\hline CL/PE-Ni-0.5 & $207-332$ & $1.68-32.08$ & 51.68 & $2.81 \times 10^{3}$ & 0.9491 \\
\hline
\end{tabular}




\begin{tabular}{cccccc} 
& $406-517$ & $40.28-96.64$ & 67.58 & $1.45 \times 10^{4}$ & 0.9861 \\
CL/PE-Ni-0.75 & $216-327$ & $2.62-30.77$ & 50.95 & $3.90 \times 10^{3}$ & 0.9456 \\
& $408-499$ & $39.93-94.19$ & 68.16 & $2.33 \times 10^{5}$ & 0.9512 \\
\hline
\end{tabular}

Note: CL-metal-X or CL/PE-metal-X represents the metal content in $1 \mathrm{~g} \mathrm{CL}$ or CL/PE is X mmol.

407

408 It is well-established that the introduction of catalyst during the co-pyrolysis of biomass

409 and plastic was favorable for lowering the activation energy of the mixture [24]. For

410 example, the E value of co-pyrolysis of CL and low density polyethylene was decreased

411 from $201.57 \mathrm{~kJ} / \mathrm{mol}$ to $168.81 \mathrm{~kJ} / \mathrm{mol}$ after the employment of HZSM-5 [31]. As shown

412 in Table 1, when transition metals were involved into the mixture CL and PE, E values

413 assigned to $\mathrm{CL}$ and $\mathrm{PE}$ in the mixture were lower than that derived from using the sole

414 feedstock (CL or PE) and that in CL/PE mixture without transition metal treatment.

415 This reveals that the presence of transition metals could promote the decomposition of

416 pure component (CL and PE) and intensify the synergistic interaction between CL and

417 PE in mixture. In particular, the $\mathrm{E}$ value of $\mathrm{CL}$ in mixture is reduced by 53.21-80.53

$418 \mathrm{~kJ} / \mathrm{mol}$ while that of PE is decreased by $8.23-12.36 \mathrm{~kJ} / \mathrm{mol}$.

420 The reduction of $\mathrm{E}$ in $\mathrm{CL}$ is larger compared to that of $\mathrm{PE}$ indicating that there was a

421 strong interaction between CL and transition metals. The influence of transition metals

422 on $\mathrm{E}$ values of $\mathrm{CL}$ and $\mathrm{PE}$ in the mixture are both subjected to the order of $\mathrm{Fe}<\mathrm{Ni}<$

$423 \mathrm{Mn}<$ Co. Moreover, it is suggested that the content of transition metal also made

424 significant influence on the $\mathrm{E}$ value of CL/PE mixture (see Table 1). With the increase

425 of Ni content, the $\mathrm{E}$ value of the mixture assigned to $\mathrm{CL}$ is gradually reduced from 69.78

$426 \mathrm{~kJ} / \mathrm{mol}$ for CL/PE-Ni-0.25 to $41.63 \mathrm{~kJ} / \mathrm{mol}$ for CL/PE-Ni-1 while that of PE in mixture 
427

428

429

430

431

432

433

434

435

exhibits a positive relationship with $\mathrm{Ni}$ content. It is indicated that high catalyst content is beneficial in promoting the decomposition of CL in mixture rather than PE in terms of the activation energy.

\section{Conclusions}

TGA was employed to investigate the thermal behavior and kinetics of co-pyrolysis of $\mathrm{CL} / \mathrm{PE}$ mixture. Different types of transition metals ( $\mathrm{Ni}, \mathrm{Co}, \mathrm{Fe}$ and $\mathrm{Mn})$ as well as different content of $\mathrm{Ni}$ as catalysts have been studied. It is found that the initial decomposition temperature of $\mathrm{CL}$ and $\mathrm{PE}$ in the mixture is decreased by $91-136^{\circ} \mathrm{C}$ and $8-15^{\circ} \mathrm{C}$, respectively, after the mixture was pre-treated with $1 \mathrm{mmol} / \mathrm{g} \mathrm{Ni}, \mathrm{Co}, \mathrm{Fe}$ or $\mathrm{Mn}$. The increase of $\mathrm{Ni}$ content resulted in the reduction of initial decomposition temperature of $\mathrm{CL}$ in $\mathrm{CL} / \mathrm{PE}$. This influence is maximized with a Ni content of 0.75 $\mathrm{mmol} / \mathrm{g}$ Ni. The presence of transition metals could intensify the synergistic interactions between CL and PE. The maximum difference of weight loss of CL and PE in transition metal treated-mixtures are $-2.99 \% \sim-14.10 \%$ and $1.30 \sim 14.41 \%$, respectively. The copyrolysis of transition metals-pretreated CL/PE mixtures can be well fitted using two consecutive first order reactions. The $\mathrm{E}$ value of $\mathrm{CL}$ and $\mathrm{PE}$ in the mixture is reduced by $53.21-80.53 \mathrm{~kJ} / \mathrm{mol}$ and $8.23-12.36 \mathrm{~kJ} / \mathrm{mol}$, respectively, as $1 \mathrm{mmol} / \mathrm{g} \mathrm{Ni}, \mathrm{Co}, \mathrm{Fe}$ or Mn were involved. With the increase of Ni content, the $\mathrm{E}$ value of $\mathrm{CL}$ in CL/PE is gradually reduced while the activation energy of PE exhibits a proportional relationship with Ni content. 
449

450

451

452

453

454

455

456

457

458

459

460

461

462

463

464

465

466

467

468

469

470

\section{Declarations of interest:}

None.

\section{Acknowledgement:}

The authors greatly acknowledge the funding support from the projects supported by National Natural Science Foundation of China (Grant no. 51476034 and 51628601), The Fundamental Research Funds for the Central Universities and Postgraduate Research \& Practice Innovation Program of Jiangsu Province from the Education Department of Jiangsu (KYCX17_0153) and Royal Society International Exchange Scheme (IE150760). The authors gratefully acknowledge financial support from China Scholarship Council.

\section{References:}

[1] Abnisa, F. and W.M.A. Wan Daud, A review on co-pyrolysis of biomass: An optional technique to obtain a high-grade pyrolysis oil. Energy Conversion and Management, 2014. 87: p. 71-85.

[2] Tripathi, M., J.N. Sahu, and P. Ganesan, Effect of process parameters on production of biochar from biomass waste through pyrolysis: A review. Renewable and Sustainable Energy Reviews, 2016. 55: p. 467-481.

[3] Gillet, S., et al., Lignin transformations for high value applications: towards targeted modifications using green chemistry. Green Chemistry, 2017. 19(18): p. 42004233. 
471

472

[4] Barbarias, I., et al., Valorisation of different waste plastics by pyrolysis and in-line catalytic steam reforming for hydrogen production. Energy Conversion and Management, 2018. 156: p. 575-584.

[5] Rivera-Austrui, J., et al., Assessment of polychlorinated dibenzo-p-dioxin and dibenzofuran emissions from a hazardous waste incineration plant using longterm sampling equipment. Chemosphere, 2011. 82(9): p. 1343-1349.

[6] Löthgren, C.-J. and B. van Bavel, Dioxin emissions after installation of a polishing wet scrubber in a hazardous waste incineration facility. Chemosphere, 2005. 61(3): p. 405-412.

[7] Kim, B.-S., et al., Catalytic Copyrolysis of Cellulose and Thermoplastics over HZSM-5 and HY. ACS Sustainable Chemistry \& Engineering, 2016. 4(3): p. 1354-1363.

[8] Chen, L., et al., Synergistic effect on thermal behavior and char morphology analysis during co-pyrolysis of paulownia wood blended with different plastics waste. Applied Thermal Engineering, 2017. 111: p. 834-846.

[9] Czernik, S. and A.V. Bridgwater, Overview of Applications of Biomass Fast Pyrolysis Oil. Energy \& Fuels, 2004. 18(2): p. 590-598.

[10] Zhang, B., et al., Production of aromatic hydrocarbons from catalytic co-pyrolysis of biomass and high density polyethylene: Analytical Py-GC/MS study. Fuel, 2015. 139: p. 622-628.

[11] Zhang, H., et al., Co-catalytic pyrolysis of biomass and waste triglyceride seed oil in a novel fluidized bed reactor to produce olefins and aromatics integrated with 
self-heating and catalyst regeneration processes. RSC Advances, 2013. 3(17): p.

494

495

496

497

498

499

500

501

502

503

504

505

506

507

508

509

510

511

512

513

514 5769-5774.

[12] Dorado, C., C.A. Mullen, and A.A. Boateng, Origin of carbon in aromatic and olefin products derived from HZSM-5 catalyzed co-pyrolysis of cellulose and plastics via isotopic labeling. Applied Catalysis B: Environmental, 2015. 162: p. $338-345$.

[13] Kositkanawuth, K., et al., Renewable Energy from Waste: Investigation of Copyrolysis between Sargassum Macroalgae and Polystyrene. Energy \& Fuels, 2017. 31(5): p. 5088-5096.

[14] Iliopoulou, E.F., et al., Catalytic upgrading of biomass pyrolysis vapors using transition metal-modified ZSM-5 zeolite. Applied Catalysis B: Environmental, 2012. 127: p. 281-290.

[15] Kim, Y.-M., et al., Catalytic co-pyrolysis of torrefied yellow poplar and highdensity polyethylene using microporous HZSM-5 and mesoporous Al-MCM41 catalysts. Energy Conversion and Management, 2017. 149(Supplement C): p. $966-973$.

[16] Hong, Y., et al., In-situ catalytic copyrolysis of cellulose and polypropylene over desilicated ZSM-5. Catalysis Today, 2017. 293: p. 151-158.

[17] Zhang, H., et al., Catalytic pyrolysis of black-liquor lignin by co-feeding with different plastics in a fluidized bed reactor. Bioresource Technology, 2015. 192: p. 68-74.

[18] Fang, S., et al., Effects of additives on the co-pyrolysis of municipal solid waste 
and paper sludge by using thermogravimetric analysis. Bioresource Technology, 2016. 209: p. 265-272.

517 [19] Liang, J., et al., Enhancement of bio-oil yield and selectivity and kinetic study of catalytic pyrolysis of rice straw over transition metal modified ZSM-5 catalyst. Journal of Analytical and Applied Pyrolysis, 2017. 128: p. 324-334.

[20] Richards, G.N. and G. Zheng, Influence of metal ions and of salts on products from 

Energy, 2017. 102, Part A: p. 134-141.

[28] Nowakowski, D.J. and J.M. Jones, Uncatalysed and potassium-catalysed pyrolysis of the cell-wall constituents of biomass and their model compounds. Journal of Analytical and Applied Pyrolysis, 2008. 83(1): p. 12-25.

[29] Khelfa, A., A. Bensakhria, and J.V. Weber, Investigations into the pyrolytic behaviour of birch wood and its main components: Primary degradation mechanisms, additivity and metallic salt effects. Journal of Analytical and Applied Pyrolysis, 2013. 101: p. 111-121.

[30] Wang, S., et al., A study on the mechanism research on cellulose pyrolysis under catalysis of metallic salts. Korean Journal of Chemical Engineering, 2007. 24(2): p. 336-340.

[31] Zheng, Y., et al., Study of the thermal behavior, kinetics, and product characterization of biomass and low-density polyethylene co-pyrolysis by thermogravimetric analysis and pyrolysis-GC/MS. Journal of Analytical and Applied Pyrolysis, 2018. https://doi.org/10.1016/j.jaap.2018.04.001. 